\title{
Multi-Objective Optimal Operation with Demand Management and Voltage Stability
}

\author{
Masahiro Furukakoi ${ }^{1 *}$, Mohammad Masih Sediqi ${ }^{1}$, Shantanu Chakraborty ${ }^{2}$, \\ Mohamed A. Moustafa Hassan ${ }^{3}$, and Tomonobu Senjyu ${ }^{1}$ \\ ${ }^{1}$ Department of Electrical and Electronics Engineering, University of the Ryukyus, \\ Okinawa 903-0213, Japan (e125511@gmail.com) * Corresponding author \\ ${ }^{2}$ Intelligent and Autonomous Systems Group, Centrum Wiskunde \& Informatica, \\ Amsterdam, The Netherlands (chakrabo@cwi.nl) \\ ${ }^{3}$ Department of Electrical Power and Machines, Cairo University, \\ Giza, Egypt (mmustfa@eng.cu.edu.eg)
}

\begin{abstract}
Due to the electric power liberalization, many power producers are entering into the deregulated power market. Most of the electrical power companies are introducing Renewable Energy Sources (RES), which will increase the power system uncertainty. Consequently, the underlyng uncertainty imposed by RES will increase the likelihood of voltage instability and voltage collapse. Also, fluctuations in supply and demand are increased by the introduction of renewable energies. On the other hand, Demand Response Program (DRP) is one of the potential solutions that reduces the power fluctuations. In this study, we proposed multi-objective optimal operation based Unit Commitment (UC) considering voltage stability and demand response. The effectiveness of the proposed method is verified by simulation results using the MATLAB.
\end{abstract}

Keywords: Multi-objective, Demand response, Voltage stability, Renewable energy source, Unit commitment.

\section{INTRODUCTION}

Nowadays Photovoltaic (PV) and Wind Generation (WG) are becoming very promising since they provide a lot of benefits to the power system as well as to the environment. However, Renewable Energy Source (RES) like PV and WG output power varies according exogenous conditions such as influence from weather. Regarding introducing a significant amount of RES, the electricity adjustment with thermal power generation facilities is necessary to continuously balancing the electricity grid. Much attention has been paid to Demand Response Program (DRP) to solve these problems. DRP can shift the peaks of demand by adjusting the demand on customer's side and enables the client's side to obtain merits by this demand adjustment. In addition, the effective use of the power transmission line is required in future to facilitate the upcoming electricity deregulation. With more efficient use of transmission lines, more sections of the power systems can be operated near voltage stability limits. Therefore the likelihood of a drop in a system voltage and voltage collapse is increased. Unit Commitment (UC) have been proposed operation in consideration of an Energy Storage System (ESS) and DRP [1-3, 5, 6]. Recently, importance to the economy has been prepared, but the importance of security is seldom reported. In the future, the UC in consideration of voltage stability and transmission network constraints will become necessary because the limitations of the power system will increase and became complicated by the introduction of power liberalization. It had been reported that single pur- pose including the maximization of the profit in conventional UC, but multi-objective optimization was unknown [16-23].

In this paper, we report multipurpose optimum operation method that minimizes the operational cost and transmission loss in the power system by introducing Electric Vehicle (EV), ESS, and DRP. Besides, voltage stability constraint was discussed. Our study shows that due to a large number of penetration of RES, conventional load curve became curve's peak load and off peak load which has been leveled by using the ESS, EV, and DRP. Also, it will be clear from this research that, the voltage stability constraints might be considered for maintaining voltage stability in every time. The MATLAB Optimization Toolbox is applied for solving the proposed method.

\section{POWER SYSTEM MODEL}

Assume the power system model shown in Fig. 1 [1]. The demand curve for PV and WG can be predicted accurately. Figure 2 demonstrates the demand for PV and WG respectively. The WG data make [1] a reference. The parameters of the generator, transmission line, EV and ESS are given in Tables 1-5 [1].

\section{PROBLEM FORMULATION}

In order to make the operative plan of EV, ESS and DRP in addition to UC at the same time, the number of the variables and constraints are increased and the scale of the optimization problem grows big. In this investigation, the big scale optimization problem is divided into 


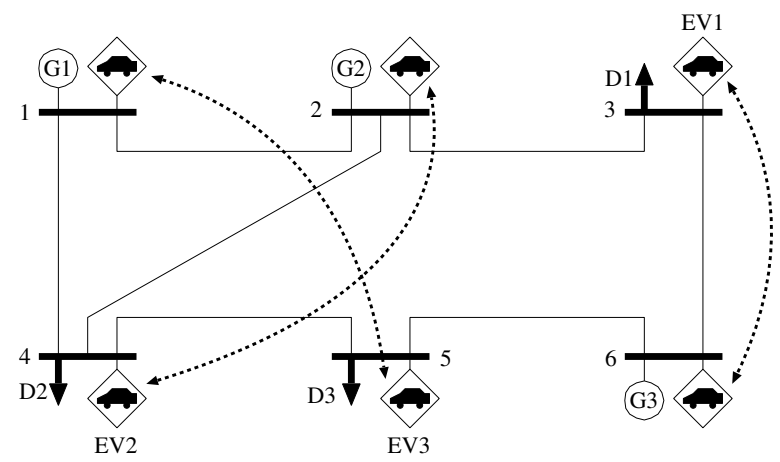

Fig. 16 bus system.

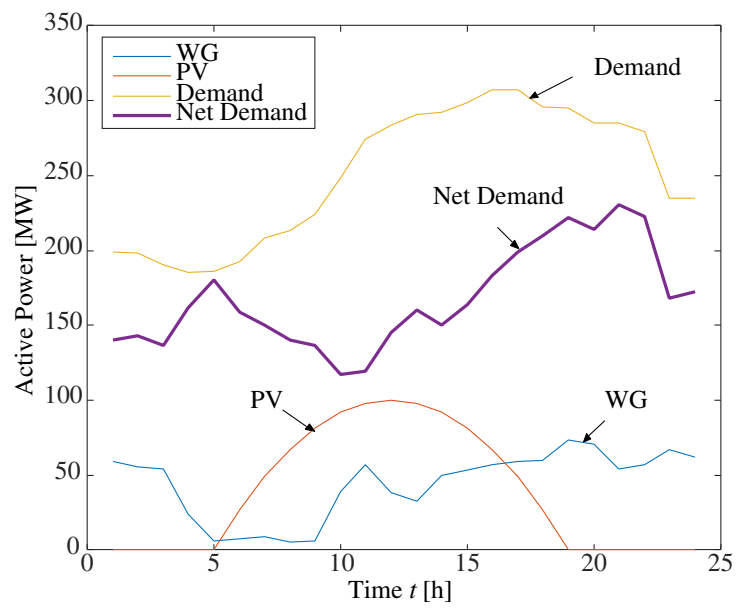

Fig. 2 Demand and RES.

Table 1 Parameters from generator

\begin{tabular}{|c|c|c|c|c|c|c|}
\hline $\begin{array}{l}\text { Unit } \\
\text { No. }\end{array}$ & $\begin{array}{l}\mathrm{a} \\
{[\$ / \mathrm{h}]}\end{array}$ & $\begin{array}{l}\mathrm{b} \\
{[\$ / \mathrm{MWh}]}\end{array}$ & $\begin{array}{l}\text { c } \\
{\left[\$ / \mathrm{MW}^{2} \mathrm{~h}\right]}\end{array}$ & $\begin{array}{l}\text { SUC } \\
{[\$]}\end{array}$ & $\begin{array}{l}\text { Pmax } \\
{[\mathrm{MW}]}\end{array}$ & $\begin{array}{l}\text { Pmin } \\
{[\mathrm{MW}]}\end{array}$ \\
\hline G1 & 176.9 & 13.5 & 0.0004 & 10 & 220 & 10 \\
\hline $\mathrm{G} 2$ & 129.9 & 32.6 & 0.001 & 200 & 100 & 10 \\
\hline G3 & 137.4 & 17.6 & 0.005 & 100 & 100 & 10 \\
\hline Unit & Qmax & Qmin & Ini & Ton & Toff & Ramp \\
\hline No. & [Mvar] & [Mvar] & State $[\mathrm{h}]$ & {$[\mathrm{h}]$} & {$[\mathrm{h}]$} & {$[\mathrm{MW} / \mathrm{h}]$} \\
\hline G1 & 200 & -200 & 4 & 4 & 4 & 55 \\
\hline $\mathrm{G} 2$ & 70 & -70 & 1 & 3 & 2 & 50 \\
\hline G3 & 50 & -50 & -1 & 1 & 1 & 20 \\
\hline
\end{tabular}

Table 2 Transmission line parameters

\begin{tabular}{llll}
\hline Line No. & $\mathrm{r}[\mathrm{pu}]$ & $\mathrm{x}[\mathrm{pu}]$ & Capacity[MW] \\
\hline $1-2$ & 0.017 & 0.17 & 200 \\
$1-4$ & 0.0258 & 0.258 & 100 \\
$2-3$ & 0.0037 & 0.037 & 100 \\
$2-4$ & 0.0197 & 0.197 & 100 \\
$3-6$ & 0.0018 & 0.018 & 100 \\
$4-5$ & 0.0037 & 0.037 & 100 \\
$5-6$ & 0.0140 & 0.14 & 100 \\
\hline
\end{tabular}

the demand management side and the supply management side.
Table 3 ESS parameters

\begin{tabular}{lr}
\hline Capacity & $300 \mathrm{MWh}$ \\
Rated output & $30 \mathrm{MW}$ \\
Initial SOC & $30 \%$ \\
SOC limits & $10 \%-90 \%$ \\
Effeciency & $95 \%$ \\
\hline
\end{tabular}

Table 4 EV parameters

\begin{tabular}{lr}
\hline Capacity & $30 \mathrm{kWh}$ \\
Rated output & $6 \mathrm{~kW}$ \\
Initial SOC & $30 \%$ \\
SOC limits & $10 \%-90 \%$ \\
Effeciency & $95 \%$ \\
Power consumption ratio & $120 \mathrm{Wh} / \mathrm{km}$ \\
Number of EVs & EV1:1,000 \\
& EV2:2,000 \\
& EV3:2,000 \\
\hline
\end{tabular}

Table 5 EV travel parameters

\begin{tabular}{|l|l|l|l|l|l|l|l|l|}
\hline \multirow{2}{*}{ EV } & \multicolumn{4}{|c|}{ First Trip } & \multicolumn{4}{c|}{ Second Trip } \\
\cline { 2 - 9 } & \multicolumn{2}{|c|}{ Depature } & \multicolumn{2}{|c|}{ Arrival } & \multicolumn{2}{|c|}{ Depature } & \multicolumn{2}{c|}{ Arrival } \\
\cline { 2 - 9 } & Time & Bus & Time & Bus & Time & Bus & Time & Bus \\
\hline 1 & $6: 00$ & 3 & $7: 00$ & 6 & $17: 00$ & 6 & $18: 00$ & 3 \\
2 & $6: 00$ & 4 & $7: 00$ & 2 & $17: 00$ & 2 & $18: 00$ & 4 \\
3 & $7: 00$ & 5 & $8: 00$ & 1 & $18: 00$ & 1 & $19: 00$ & 5 \\
\hline
\end{tabular}

\subsection{Demand management side}

The objective function and constraints of demand management side would be as follows. For the optimization of this problem the MATLAB Optimization Toolbox (internal point method).

\subsubsection{Objective function}

The objective function of the issue of demand management side is to minimize a difference between maximum power $P_{D}^{\max }$ and minimum power $P_{D}^{\min }$ of daily load demand.

$$
\text { minimize } F_{1}=P_{D}^{\max }-P_{D}^{\min }
$$

\subsubsection{Constraints}

- EV constraints

$$
\begin{gathered}
C_{E V}^{\min } \leq C_{E V}(t) \leq C_{E V}^{\max } \\
0 \leq\left|P_{E V}(t)\right| \leq P_{E V}^{\max } \\
C_{E V}(t)= \\
C_{E V}(t-1)-\frac{P_{E V}(t)}{\eta_{E V}}, P_{E V}(t) \geq 0 \\
C_{E V}(t-1)-P_{E V}(t) \eta_{E V}, P_{E V}(t)<0
\end{gathered}
$$
where, $C_{E V i}, P_{E S i}$ and $\eta$ are the capacity of $\mathrm{EV}$ energy storage system $i$, the power of EV energy 
storage system $i$ and efficiency of EV energy storage system, accordingly. The formulation is different according to the charge and discharge. In addition, ESS uses $3.6 \mathrm{kWh}$ per hour during to drive an EV.

- ESS constraints

$$
\begin{gathered}
C_{E S S}^{\min } \leq C_{E S S}(t) \leq C_{E S S}^{\max } \\
0 \leq\left|P_{E S S}(t)\right| \leq P_{E S S}^{\max } \\
C_{E S S}(t)= \\
C_{E S S}(t-1)-\frac{P_{E S S}(t)}{\eta_{E S S}}, P_{E S S}(t) \geq 0
\end{gathered}
$$$$
C_{E S S}(t-1)-P_{E S S}(t) \eta_{E S S}, P_{E S S}(t)<0
$$

where, $C_{E S S i}, P_{E S S i}$ and $\eta$ are the capacity of ESS $i$, the power of ESS $i$ and efficiency of ESS, accordingly.

- DRP constraints [2,3]

The load of the consumers before and after DRP are shown in Fig. 3. The hatched area in Figure 3 illustrates the load has moved from another time interval at time $t$. The yellow area does not participate in the DRP at time $t$, and it also shows that some of the load have not yet been moved to the other time interval. The demand $D(t)$ after the application can formulate DRP as follows.

$$
D(t)=d r(t)+(1-D R(t)) D_{0}(t)
$$

Here, in $d r(t)$, in load, $D R(t)$ which moved to $\mathrm{t}$ from other time at the time, participation rate of DRP in $t, D_{o}(t)$ are load before the DRP application in $t$ at the time at the time.

$$
D R(t) \leq D R_{\max }
$$

Eq. (11) limits the load shifting in every other time. $D R_{\max }$ shows the biggest participation rate of consumers of DRP. The price elasticity of electricity demand is inelastic [4]. For this reason, $D R_{\max }=0.2$ is assumed in this article;

$$
\begin{aligned}
& |\Delta D(t)| \leq D_{\text {rate }} D_{0}(t) \\
& \Delta D(t)=D(t)-D_{0}(t)
\end{aligned}
$$

where, $\Delta D$ is before DRP application, change load quantity after the DRP application, $D_{\text {rate }}$ shows maximum load regulation. In this article, $D_{\text {rate }}=0.2$ is assumed.

$$
\sum_{t=1}^{24} d r(t)=\sum_{t=1}^{24} D R(t) D_{0}(t)
$$

Eq. (14) indicates that before and after application of DRP, the total load does not change. Also, it prevents the reduction of income before the introduction of EV, ESS and DRP.

\subsection{Supply management side}

The objective function and constraints of supply management side would be as follows. For the optimization of this problem the MATLAB Optimization Toolbox (GA) was used. The GA can solve mixed integer nonlinear problem that includes a non-linear constraints (e.g., voltage stability constraints).

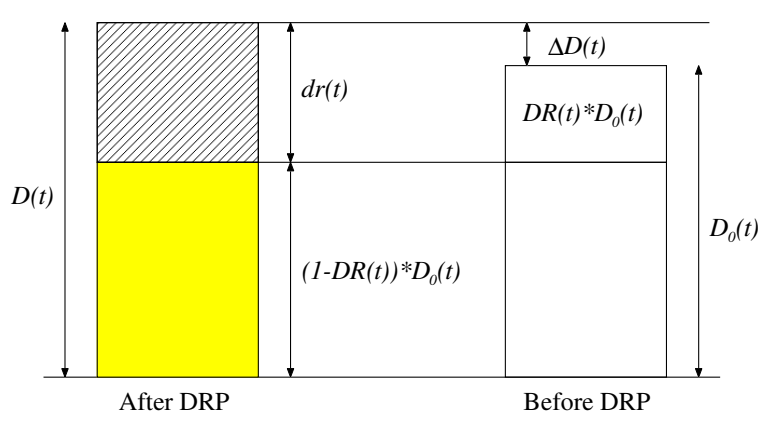

Fig. 3 Demand response program.

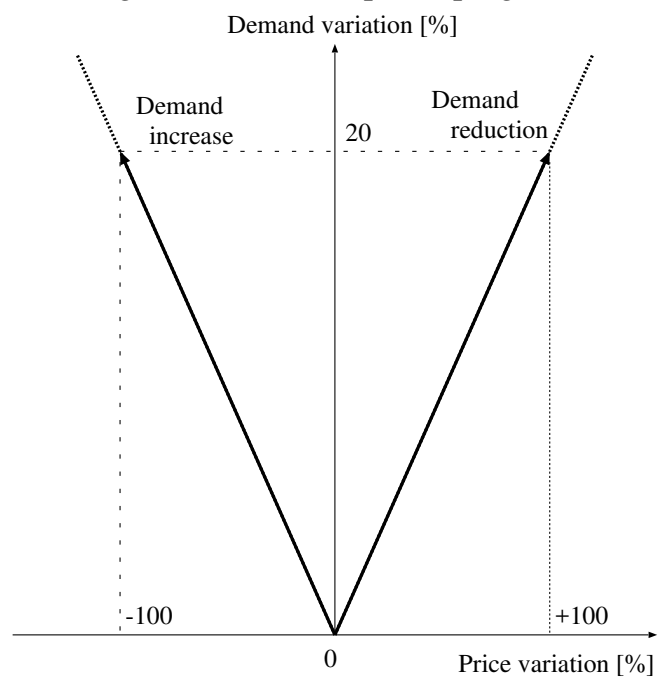

Fig. 4 Price elasticity.

\subsubsection{Objective function}

Eq. (15) is the transmission line losses for the one day. Eq. (16) is the operating cost.

$$
\begin{aligned}
& \sum_{t=1}^{N T} \sum_{l=1}^{L} \operatorname{LOSS}_{l} \\
& \sum_{t=1}^{N T} \sum_{i=1}^{N G} F C_{i}\left(P G_{i}\right)+S U C_{i}(t)
\end{aligned}
$$

where, $L O S S_{l}, F C_{i}\left(P G_{i}(t)\right), S U C_{i}(t), N T, L$ and $N G$ are transmission loss of the line $i$, generation cost for unit $i$ at time $t$, start up cost of unit $i$ at time $t$, number of scheduling hours, number of transmission lines and number of generating units, respectively. The cost function of generating units are shown in Eq. (17).

$$
F C_{i}\left(P G_{i}(t)\right)=a_{i}+b_{i} P G_{i}(t)+c_{i} P G_{i}^{2}(t)
$$

where, $F C_{i}, P G_{i}, a_{i}, b_{i}$ and $c_{i}$ are fuel cost for unit $i$, active power output for unit $i$, fuel cost coefficients for unit $i$, accordingly.

\subsubsection{Constraints}

- Generator active/reactive power output constraints

$$
P G_{i}^{\text {min }} \leq P G_{i}(t) \leq P G_{i}^{\max }
$$




$$
Q G_{i}^{\min } \leq Q G_{i}(t) \leq Q G_{i}^{\max }
$$

where $P G_{i}^{\min }$ and $P G_{i}^{\max }$ are the lower and upper limits for active power generation unit $i$, and $Q G_{i}^{\text {min }}$ and $Q G_{i}^{\max }$ are the lower and upper limits for reactive power generation unit $i$.

- The Min-up and Min-down time constraints

$$
\begin{aligned}
& T_{i}^{o n} \leq X_{i}^{\text {on }}(t) \\
& T_{i}^{\text {off }} \leq X_{i}^{\text {off }}(t)
\end{aligned}
$$

where, $T_{i}^{o n}, T_{i}^{o f f}, X_{i}^{o n}(t)$ and $X_{i}^{o f f}(t)$ are on- and off-time limits of unit $i$, on- and off-time of unit $i$ at time $t$.

- $\mathrm{AC}$ power flow equation constraints

$$
\begin{aligned}
& P G_{i}-P L_{i} \\
& =V_{i} \sum_{k=1}^{N} V_{k}\left\{G_{i k} \cos \left(\theta_{i}-\theta_{k}\right)\right. \\
& \left.+B_{i k} \sin \left(\theta_{i}-\theta_{k}\right)\right\} \\
& Q G_{i}-Q L_{i} \\
& =V_{i} \sum_{k=1}^{N} V_{k}\left\{G_{i k} \sin \left(\theta_{i}-\theta_{k}\right)\right. \\
& \left.-B_{i k} \cos \left(\theta_{i}-\theta_{k}\right)\right\}
\end{aligned}
$$

where, $P G_{i}, Q G_{i}, P L_{i}, Q L_{i}, \theta_{i}, G_{i k}$ and $B_{i k}$ are active and reactive powers are produced by generator $i$, active and reactive powers are consumption by teh demand $i$, voltage angle in bus $i$, real and imaginary parts of the $i k$ elements of the node admittance matrix, respectively.

- Bus voltage constraints

$$
0.9 \mathrm{pu} \leq \mathrm{V}_{\mathrm{i}}(\mathrm{t}) \leq 1.1 \mathrm{pu}
$$

The $V_{i}(t)$ is voltage of bus $i$ at time $t$.

- Transmission capacity constraints

$$
S_{\text {line }}(t) \leq S_{\text {line }}^{\max }
$$

The $S_{\text {line }}(t)$ is active power flow of line at time $t$.

- Voltage stability constraints [10]

$$
0.3 \mathrm{pu} \leq \min \{\Delta P(t), \Delta Q(t)\}
$$

where, $\Delta P$ and $\Delta Q$ are voltage stability indexes.

\section{SIMULATION RESULTS}

\subsection{Simulation result of Demand management side}

Simulation results shows a comparison of the system load which has been described in Table 6 . Figure 5 shows the load demand curve which introduced EV, ESS and DRP. Figure 6 illustrates the state of charge (SOC) of EV. Figure 7 shows an electric bill before and after DRP. Also, Figs. 6-7 are simulation results introduced EV, ESS and DRP. The electric bill set the price elasticity of demand as 0.2 (Fig. 4). The change of the load demand for the original taste that deducted PV, electricity of WG from load demand than Fig. 4 because PV, WG are introduced in large quantities grows big. As can be seen from the Fig. 2 , due to introducing a large amount of regenerative energy, the net demand fluctuation is increased. As shown in Fig. 5, it was found, that to provide a net demand amount of leveling by introducing EV, ESS and DRP. Introducing EV, ESS and DRP leads to suppressing rapid
Table 6 Comparison of system load

\begin{tabular}{|l|lllll|}
\hline & Orig. & DRP & ESS & EV & All \\
\hline Revenue $\left[\times 10^{3} \$\right]$ & 805 & 805 & 805 & 813 & 805 \\
Load factor[\%] & 72.6 & 76.1 & 83.5 & 83.8 & 98.5 \\
Peak reduction[\%] & 0 & 4.5 & 13.0 & 12.4 & 26.2 \\
Peak-Valley Reduction[\%] & 0 & 8.0 & 30.7 & 30.1 & 47.8 \\
\hline
\end{tabular}

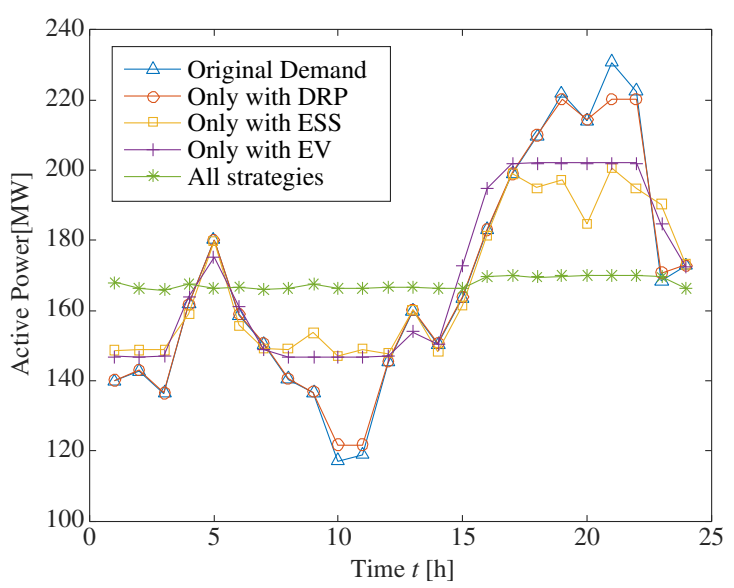

Fig. 5 Demand fluctuations.

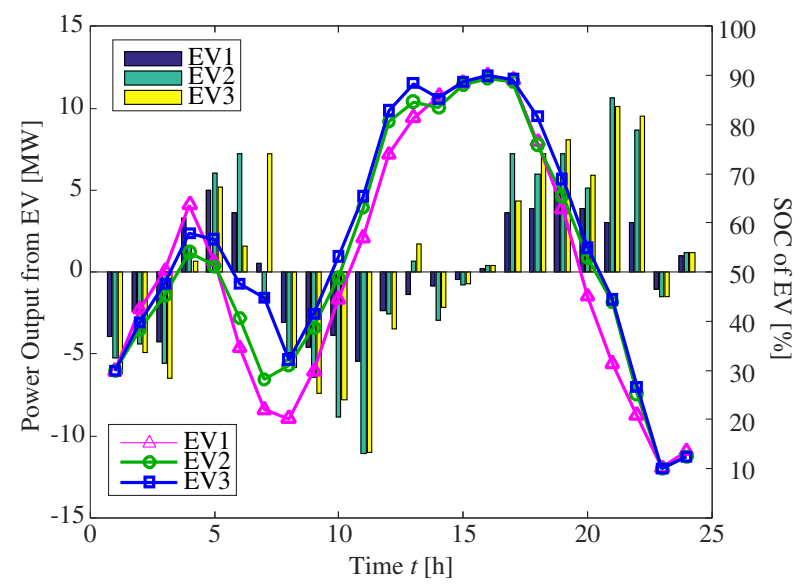

Fig. 6 EV output and SOC.

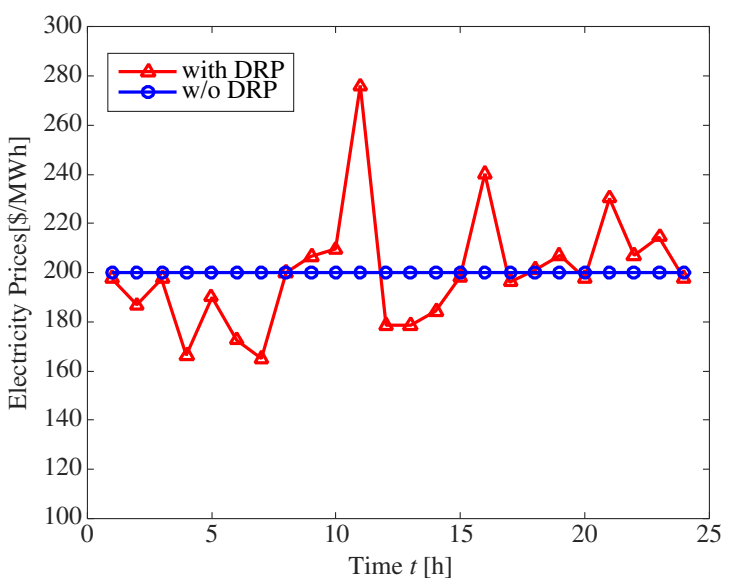

Fig. 7 Electric Prices.

variations in loads. Furthermore, a better load shifting in harmony by controlling the EV, ESS and DRP can be seen. 
Table 7 Simulation conditions

\begin{tabular}{ll}
\hline Case & Simulation conditions \\
\hline 1 & with Voltage stability, w/o Demand management \\
2 & with Voltage stability, with Demand management \\
3 & w/o Voltage stability, with Demand management \\
\hline
\end{tabular}

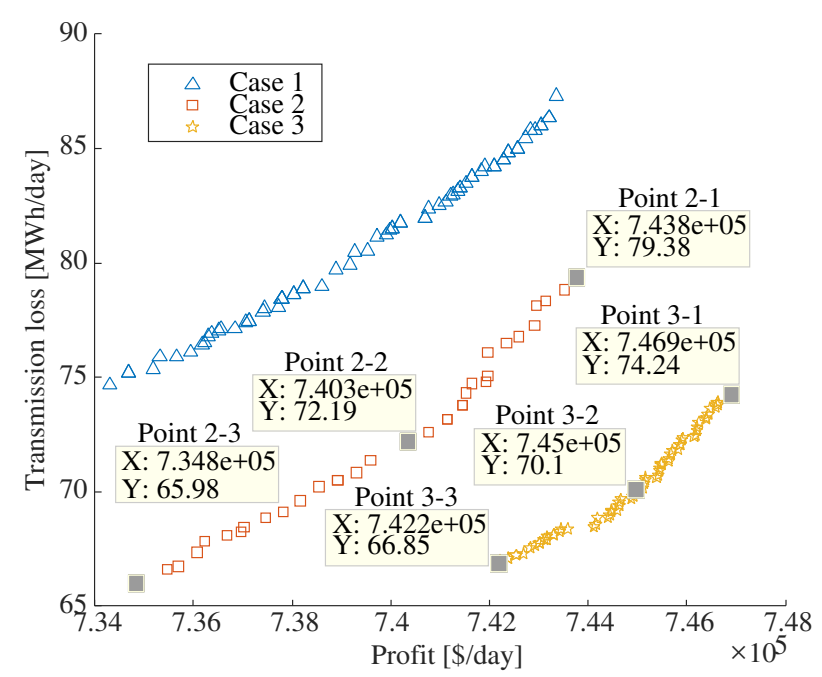

Fig. 8 Pareto front for different cases.

\subsection{Simulation result of Supply management side}

Table 7 displays the simulation conditions for different cases. Figure 8 shows the Pareto optimal solution for each case. The voltage stability is demonstrated in Fig. 9, obtained a solution selected from the Pareto optimal solution for each case in Fig. 8. The voltage stability index shows only an index of the active power because the index of reactive power became the value that is relatively larger than $0.3 \mathrm{pu}$. It confirmed that the demand management provided a better Pareto optimum solution in Case 2 are compared to Case 1 in Fig. 8. It also confirmed that a better Pareto optimum solution in Case 3 was provided by without voltage stability constraints as compared to Case 2 in Fig. 8. However, Case 3 in Fig. 9 produces the time when a voltage stability is low. As can be seen from Fig. 9, to provide a scheduling maintained voltage stability, a voltage stability constraints in Case 2 should be taken into account.

\section{CONCLUSION}

In this research, we examined a UC in consideration of a large number of constraints by dividing demand management side and supply management side. The sudden variation of a load by mass introduction of RES from simulation results was possible to be eliminated by demand management. Furthermore, it was shown that it is feasible to realize the operation of the power system to improve the voltage stability by considering voltage stability constraints.

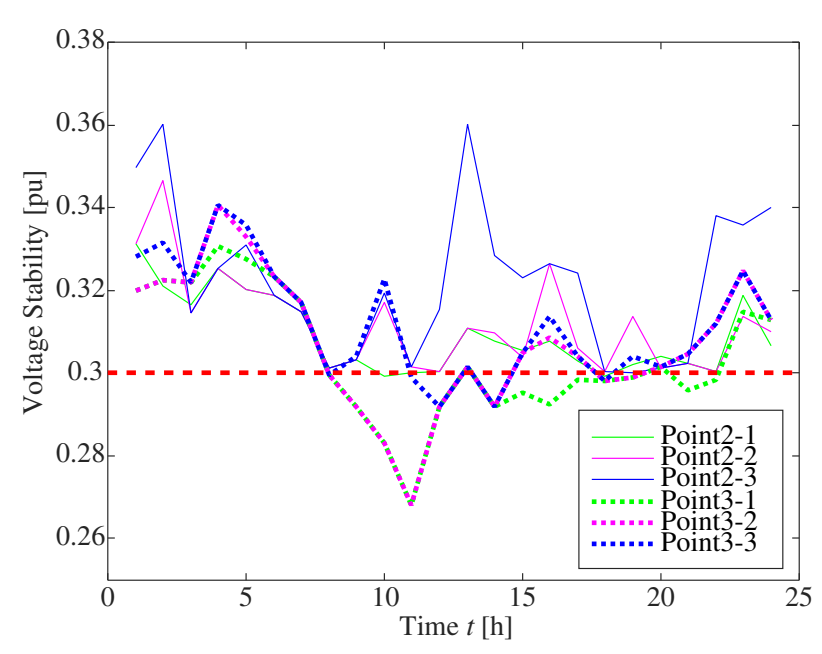

Fig. 9 Voltage stability.

\section{REFERENCES}

[1] Mohammad E. Khodayar, LeiWu, and Mohammad Shahidehpour," Hourly Coordinationof Electric Vehicle Operation and Volatile Wind Power Generation in SCUC", IEEE Transactions on Smart Grid, vol. 3, no. 3, pp. 1271-1279, September, 2012.

[2] Manijeh Alipour, Kazem Zare, and Behnam Mohammadi-Ivatloo," Short-term scheduling of combined heat and power generation units in the presence of demand response programs", Energy, vol. 71, iss. C, pp. 289-301, 2014.

[3] Tan Zhong-fu, Song Yi-hang, Zhang Hui-juan, Shi Quan-sheng, and Xu Jun," Joint optimization model of generation side and user side based on energysaving policy", International Journal of Electrical Power \& Energy Systems, vol. 57, pp. 135-140. May, 2014.

[4] Okajima S, Okajima H, “ Estimation of Japanese price elasticity of residential electricity demand, 1990-2007”, Energy Economics 40:pp. 433-440, 2013

[5] Hossein Haroonabadi," Unit Commitment in Smart Grid Considering Demand Response and Stochastic Wind Generation", J. Energy Power Sources, vol. 1, no. 6, pp. 314-320, 2014.

[6] Cem Sahin, Mohammad Shahidehpour, and Ismet Erkmen," Allocation of Hourly Reserve Versus Demand Response for Security-Constrained Scheduling of Stochastic Wind Energy", IEEE Transactions on Sustainable Energy, vol. 4, no. 1, pp. 219-228, January, 2013.

[7] Harun Or Rashid Howlader, Hidehito Matayoshi and Tomonobu Senjyu, "Thermal Units Commitment Integrated with Reactive Power Scheduling for the Smart Grid Considering Voltage Constraints", International Journal of Emerging Electric Power Systems, vol. 16, iss. 4, pp. 323-330, June, 
2015.

[8] D. Xu and L. Kang, "Optimal Dispatch of Unreliable Electric Grid-Connected Diesel GeneratorBattery Power Systems", International Journal of Emerging Electric Power Systems, vol, 16, iss. 3, pp. 253-263, May, 2015.

[9] S. Surender Reddy, A. R. Abhyankar and P. R. Bijwe, "Co-optimization of Energy and Demand-Side Reserves in Day-Ahead Electricity Markets", International Journal of Emerging Electric Power Systems, vol. 16, iss. 2, pp. 195-206, March, 2015.

[10] Masato Tachibana, Michael Damien Palmer, Tomonobu Senjyu and Toshihisa Funabashi," Voltage Stability Analysis and (P,Q)-V Characteristics of Multi-bus System", CIGREAORC Technical Meeting, 2014.

[11] Mojtaba Khederzadeh and Mohammad Khalili, "High Penetration of Electrical Vehicles in Microgrids: Threats and Opportunities", International Journal of Emerging Electric Power Systems, vol. 15, iss. 5, pp. 457-469, September, 2014.

[12] M. Basu, "Multi-objective Differential Evolution for Dynamic Economic Emission Dispatch", International Journal of Emerging Electric Power Systems, vol. 15, iss. 2, pp. 141-150, March, 2014.

[13] Shenghu Li, "Configuration of Jacobian Matrix in Steady-State Voltage Stability Analysis Based on Rotor Flux Dynamics of Rotating Machines", International Journal of Emerging Electric Power Systems, vol. 14, iss. 3, pp.239-244, June, 2013.

[14] Mir Sayed Shah Danish, Atsushi Yona and Tomonobu Senjyu, “A Review of Voltage Stability Assessment Techniques with an Improved Voltage Stability Indicator", International Journal of Emerging Electric Power Systems, vol. 16, iss. 2, pp.107115, April, 2015.

[15] Hao Quan, Dipti Srinivasan, Ashwin M. Khambadkone, and Abbas Khosravi, "A computational framework for uncertainty integration in stochastic unit commitment with intermittent renewable energy sources", Applied Energy, Vol. 152, pp. 71-82, August, 2015.

[16] C. M. Correa-Posada, G. Morales-Espaa, P. Dueas and P. Snchez-Martn, ”Dynamic Ramping Model Including Intraperiod Ramp-Rate Changes in Unit Commitment," in IEEE Transactions on Sustainable Energy, vol. 8, no. 1, pp. 43-50, Jan. 2017.

[17] H. Khorramdel, J. Aghaei, B. Khorramdel and P. Siano, "Optimal Battery Sizing in Microgrids Using Probabilistic Unit Commitment," in IEEE Transactions on Industrial Informatics, vol. 12, no. 2, pp. 834-843, April 2016.

[18] G. Morales-Espaa, R. Baldick, J. Garca-Gonzlez and A. Ramos, "Power-Capacity and RampCapability Reserves for Wind Integration in Power-
Based UC," in IEEE Transactions on Sustainable Energy, vol. 7, no. 2, pp. 614-624, April 2016.

[19] C. Wanget al., "Robust Risk-Constrained Unit Commitment With Large-Scale Wind Generation: An Adjustable Uncertainty Set Approach," inIEEE Transactions on Power Systems, vol. 32, no. 1, pp. 723-733, Jan. 2017.

[20] Y. Sun, J. Zhong, Z. Li, W. Tian and M. Shahidehpour, "Stochastic Scheduling of Battery-Based Energy Storage Transportation System With the Penetration of Wind Power," in IEEE Transactions on Sustainable Energy, vol. 8, no. 1, pp. 135-144, Jan. 2017.

[21] H. Abdi, E. Dehnavi and F. Mohammadi, "Dynamic Economic Dispatch Problem Integrated With Demand Response (DEDDR) Considering Non-Linear Responsive Load Models," in IEEE Transactions on Smart Grid, vol. 7, no. 6, pp. 2586-2595, Nov. 2016.

[22] Nikmehr, Nima, Sajad Najafi-Ravadanegh, and Amin Khodaei. "Probabilistic optimal scheduling of networked microgrids considering time-based demand response programs under uncertainty." Applied Energy 198 (2017): 267-279.

[23] Jiang, Yibo, et al. "Day-ahead stochastic economic dispatch of wind integrated power system considering demand response of residential hybrid energy system.” Applied Energy 190 (2017): 1126-1137. 